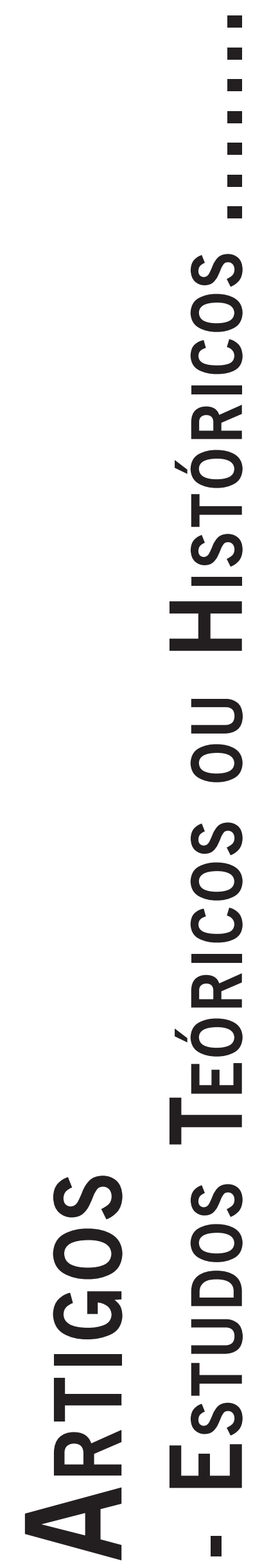




\title{
REFLEXÃO FENOMENOLÓGICA SOBRE A ALUCINAÇÃO E SEU SENTIDO
}

\author{
Phenomenological reflection on the hallucination and its meaning
}

Reflexión fenomenológica en la alucinación y su significado

Carlos Augusto Serbena

FELIPE MONTRUCCHIO ILKIU

\begin{abstract}
Resumo: Alucinação define-se como ‘percepção sem estímulo’ ou erro na percepção. Ela abarca a indagação sobre o que é existente e 'real' ou ilusão. Deste modo, neste trabalho são realizadas reflexões sobre o sentido do alucinar a partir da fenomenologia apoiando-se principalmente em Jaspers, Heidegger e Merleau-Ponty. A presença e a constância da alucinação indicam perturbação na experiência de realidade do alucinado, um fenômeno de interrupção das possibilidades, na qual se privilegia em excesso o mundo subjetivo. O alucinado constrói uma realidade que não possui a profundidade vivida ou experienciada encontrada nas relações com o mundo real compartilhado. Entretanto possui um sentido, pois é a expressão existencial de um vivido. A alucinação como patologia existencial auxilia a subverter a concepção clássica e cartesiana do ego, apontando para a comunhão pré-reflexiva entre o sujeito e o mundo. Assim, ela não se conforma a uma explicação causal, mas se configura como um modo de ser do sujeito no encontro com o mundo e, assim, possui o caráter da expressão de um sentido e de uma tomada de posição do sujeito diante da realidade, sendo fundamental investigar fenomenologicamente como se dá para uma consciência ser palco de um mundo onde a alucinação é possível.
\end{abstract}

Palavras-chave: Alucinações; Fenomenologia; Existencialismo; Sentido.

Abstract: Hallucination is defined as "perception without stimulation" or one fail in perception. It is related with what is "real" or illusion in the experience. Thus, this work makes reflections on the meaning of hallucinate in phenomenology basing primarily on Jaspers, Heidegger and Merleau-Ponty. The presence and constancy of hallucination indicate a disturbance in the reality's experience of subject than hallucinates. This is a phenomenon of interruption of possibilities, in which he privileges the subjective world. The person who hallucinates constructs a reality that has not the depth lived or experienced found in the relations on the shared real world. However has a sense because it is the existential expression of an lived. Hallucination as pathology helps to subvert classical and Cartesian conception of the self, pointing to the pre-reflective communion between subject and world. It does not conform to a causal explanation but is configured as a mode of being of the subject in the encounter with the world. It has the feature of the expression of a direction and a position of the person about the reality. It is fundamental to investigate the configuration of a conscience on the fact venue of one world where the hallucination is possible.

Keywords: Hallucinations; Phenomenology; Existencialism; Meaning.

Resumen: Alucinación se define como "percepción sin estimulación” o una falla en la percepción. Está relacionado con lo que es "real" o la ilusión de la experiencia. Por lo tanto, este trabajo hace reflexiones sobre el significado de alucinar en la fenomenología basando principalmente en Jaspers, Heidegger y Merleau -Ponty. La presencia y constancia de alucinación indican alteraciones en la experiencia de la realidad del sujeto que alucina. Este es un fenómeno de la interrupción de las posibilidades, en la que los privilegios del mundo subjetivo. la persona que alucina construye una realidad que no tiene la profundidad vivido o experimentado que se encuentra en las relaciones en el mundo real compartida. Sin embargo tiene un sentido, ya que es la expresión existencial de un vivido. Alucinación como patología ayuda a subvertir la concepción clásica y cartesiana del yo, que apunta a la comunión pre-reflexiva entre el sujeto y el mundo. No se ajusta a una explicación causal, sino que se configura como un modo de ser del sujeto en el encuentro con el mundo. Tiene la característica de la expresión de una dirección y una posición de la persona acerca de la realidad. Es fundamental para investigar la configuración de una conciencia sobre el lugar hecho de un mundo en el que es posible la alucinación.

Palabras-clave: Alucinaciones; Fenomenología; Existencia; Significado.

\section{Introdução}

Em 13 de maio de 1917, em Fátima - Portugal, três crianças apascentavam um rebanho quando Virgem Maria apareceu a elas pela primeira vez. Houve outras aparições e a última se realizou em 13 de outubro do mes- mo ano diante de 70.000 pessoas. Este fato desencadeou diversos desdobramentos, como as famosas profecias de Fátima, a construção de capelas e o início de uma devoção. A realidade destas aparições e profecias não é questionada por quem é católico apostólico romano ou por quem acredita na Virgem Maria; entretanto para aqueles 
que não partilham da mesma crença este fato não é real, é uma ilusão ou um delírio coletivo. Este exemplo procura mostrar como a experiência da realidade varia de acordo com a significação do fenômeno e, deste modo, a realidade pode ser problematizada pelos sonhos, delírio, imaginação e alucinação. Uma das dificuldades de se compreender a alucinação é que ela sobrevive no 'nó’ da especulação sobre o que é real e o que é irreal. Ela está no meio da indagação sobre o que é de fato existente - e 'real' ou ilusão - como o resultado de nossa criação, como o sonho e a imaginação. Deste modo, neste trabalho, é realizada uma reflexão sobre o sentido do alucinar a partir da fenomenologia apoiando-se principalmente em Jaspers, Heidegger e Merleau-Ponty.

Pode-se colocar a alucinação como própria de transtornos mentais, entretanto ela não se apresenta como incomum (Menezes Jr. \& Moreira-Almeida, 2009). O pensamento normal do ser humano em certa medida também é delirante (Parra, 2008), por exemplo, quando desconsideramos a realidade para nos apegarmos a construções mais apreciadas, mais confortáveis; ou nas fantasias que criavam os povos primitivos, ou naquelas que criamos em nossa sociedade (Jaspers, 1987).

Em relação a este encontro da realidade com o mundo subjetivo, deve-se atentar para duas considerações. A primeira é abranger os dois pólos da relação entre o sujeito ou a consciência e seu objeto, a alucinação (Pérola, 2006). Deste modo, atentar justamente para a relação originária e constituinte da consciência com o mundo, afastando o "realismo ingênuo" do positivismo ou a "negação do mundo" de um espiritualismo (Luijpen, 1973). A segunda é relembrar que o sujeito no mundo, o ser-aí, é sempre em situação, em um determinado ponto de vista, vinculado a um projeto e um sentido (Merleau-Ponty, 1994), que não existe uma neutralidade a priori ou um ponto de Arquimedes que a partir do qual podemos avaliar o real e o mundo. Assim, a alucinação se insere em um questionamento e reflexão sobre a constituição do mundo e da realidade para o sujeito que alucina.

\section{A Alucinação na Psiquiatria}

O termo "alucinação" foi cunhado pelo alienista francês J. D. E. Esquirol em 1838 (Kolb, 1986) e auxiliou a consolidar a ideia de loucura como doença. A psiquiatria catalogou diversos tipos de alucinações, sendo diferenciados catorze tipos (Kaplan, 1997). As alucinações, juntamente com o delírio, o embotamento e o discurso desorganizado caracterizam tipicamente a esquizofrenia e outras psicoses. Entretanto, não se consideram patológicas as alucinações hipnagógicas (ao adormecer), as pseudoalucinações em crianças (interpretadas como imaginação) e as alucinações eidéticas (memória ‘fotográfica'), conforme Kolb (1986). Assim temos alucinações patológicas e não patológicas, mas qual o limite entre elas? É um fenômeno a rigor patológico? No exame psíquico de saúde mental, a alucinação se refere a um distúrbio na função de sensopercepção (Ramos, 2006).

Caracterizando, as ilusões são casos em que a pessoa confunde um estímulo (objeto) existente por outro, como exemplo quando se toma uma bola rolando por um rato; se é advertido, o sujeito corrige a percepção e deixa de crer na ilusão. As alucinações podem ser diferenciadas (Jaspers, 1987). Alucinação verdadeira é perceber um objeto, que não existe, e tomá-lo como existindo corporal e objetivamente; além disso, aparece sem a 'autorização' do sujeito, sem sua vontade; possui 'frescor' ou seja, aparece como um objeto real, colorido (e não, por exemplo, embaçado ou em uma tonalidade parda). Já nas pseudo-alucinações o sujeito também é passivo (é arrebatado pela percepção, sem seu consentimento), a imagem é nítida e detalhada, e é completa, assim como na alucinação verdadeira; porém carecem de espacialidade e corporeidade, ou seja, não existem objetivamente no espaço para o indivíduo. Elas não são percepções sensíveis, mas se constituem, segundo Jaspers (1987), uma espécie 'curiosa' de percepção. Entretanto, as representações são um oposto das alucinações verdadeiras, pois não possuem nem objetividade e nem corporeidade. Elas dependem da vontade do sujeito (não sendo passivas) nem sempre são nítidas ou detalhadas e não são constantes (Jaspers, 1987). Assim temos neste entendimento, a alucinação considerada como uma falha, um desvio da imaginação ou da percepção, como um sinal ou sintoma externo ao sujeito.

A tradição filosófica sempre deu prioridade à imaginação reprodutora, considerando-a como um resíduo do objeto percebido que permanece retido em nossa consciência. A imagem seria um rastro ou um vestígio deixado pelo estímulo na percepção (Chaui, 2000). Descartes, por exemplo, afirma na Segunda Meditação que "imaginar nada mais é do que contemplar a figura ou a imagem de uma coisa cor-poral” (Descartes, 1641/1983, p. 122). Ela aparece como vinculada ao corpo, um possível desvio ou fonte de erro da apreciação das ideias claras e distintas, mas dependente da consciência do sujeito que certifica sua existência pelo pensar (Hebeche, 2005). Para os empiristas, as imagens são derivadas, tais como reflexo ou recordação das percepções ou sensações, e que segundo Locke, "a alma começa a ter ideias quando começa a perceber” (1690/1999, p. 60) e que "a percepção é a entrada de todos os materiais do conhecimento" (1690/1999, p. 80). Assim, tanto o empirismo como o racionalismo possuem uma visão redutiva da imaginação na medida em que ela reproduz a percepção na esfera do conhecimento e repete indiretamente a percepção no campo da fantasia (Chaui, 2000).

Deste modo, a alucinação - como desvio da imaginação - pode ser considerada essencialmente como um erro na percepção do mundo, uma falha na apropriação dos dados do mundo exterior, diferentemente do delírio que é falso juízo, com crença inabalável pela lógica ou argumentação. 
Entretanto esta consideração apresenta problemas. Segundo Amaral (2007), não se chega a um consenso científico sobre as diferenças entre, por exemplo, alucinação, 'representações', pseudoalucinação e outras derivações da 'percepção sem objeto', cuja sua definição possui críticas. Segundo Amaral (2007), os paradoxos encontram-se apenas em níveis conceituais e de tradução, entretanto acreditamos que hajam mais concepções mal formuladas dentro do tema. Além do mais, segundo Kolb (1986), ao alucinar ocorre o delírio, no sentido que a falsa percepção seria (também?) uma falha de juízo. Nota-se que, quando não há objeto, não há efetivamente percepção; além disso, o que é traduzido como percepção para o português equivale literalmente ‘tomar como verdade’ para a língua alemã, entre outras ambiguidades que surgem (Amaral, 2007). Esta concepção da patologia da percepção pode então ser mais esmiuçada desde seus primórdios na literatura.

Como exemplo desta imprecisão, Jaspers (1987) diferencia várias formas de anormalidade da percepção, que partem da mais originária até formas mais elaboradas de distúrbio. Por exemplo, ele cita alterações na percepção (que nem sempre são alucinações propriamente ditas) que promovem um afeto bastante diferente do normal, percebido como incomum inclusive ao próprio sujeito; as alterações da intensidade do estímulo (barulhos muito mais altos, ou baixos, luzes também) - estas podem ser consideradas, a nosso ver, como espécies de alucinação; há a divisão da percepção (uma sonoridade ou cor deixa de ser atribuída ao objeto respectivo); as falsas recordações (que por alguns é chamada de alucinação da memória); há também as cognições corpóreas alteradas, as quais poderiam ser usadas como exemplos de alucinação tátil; há por fim as falsas-percepções, que se dividem em ilusões, alucinações verdadeiras e pseudo-alucinações.

Próximo, mas distinto da alucinação encontra-se o delírio, que pode ser considerado como falso juízo, onde, entretanto, há concomitante alteração na personalidade (emoção). O sujeito, além de possuir falsas crenças, se torna extremista (pequenos detalhes assumem importância desproporcional) e inabalável em sua convicção, sem ceder de seu ponto de vista sob quaisquer argumentos, "mesmo que 'lógicos"” (no caso de alguém extremamente ciumento, pode haver delírio por mais que o ciúme tenha sua constatação de realidade), segundo Jaspers (1987).

A alucinação também é vista muitas vezes como 'falta de juízo'; entretanto Merleau-Ponty (1994) critica a concepção comum de 'juízo' como veracidade da experiência, o que combate esta concepção objetivista. Da mesma forma, delimitar as percepções falsas e verdadeiras é tirar a veracidade da evidência da experiência, e atribuir ao mundo uma realidade em-si, à qual aqui aborda-se com cuidado, pois desconsideraria o fenômeno tal como é percebido num encontro da consciência com o mundo. Sempre teremos uma noção do que seja alucinação ou delírio, daquilo que se difere por ter clareza ou qualidade concreta. Entretanto esse não é um julgamento a posteriori, mas que se intui no próprio experienciar do sonho, da imaginação e da realidade como afirma Merleau-Ponty (1994). Lembrando que a experiência possui uma evidência que nos conecta a algo que, quando experienciado, pode ser chamado de real, Isto ocorre devido ao fato de o percebemos como evidente, por mais que suspeitemos que seja uma percepção ilusória (Merleau-Ponty, 1994, p. 381).

\section{Alucinação, Patologia e Realidade}

A alucinação, como demonstraremos, é patológica a partir do ponto que reduz as variedades do ser - enquanto ser corporal e intersubjetivo - em sua apropriação do mundo; ela possui estrutura que se diferencia da percepção comum nas suas vivências; e só é entendida existencialmente se reconhecida enquanto fenômeno constituído de sentido para o sujeito que a alucina.

Considera-se que a presença e a constância da alucinação indicam uma perturbação na experiência da própria realidade do alucinado e prejudicam assim sua saúde. Heidegger, nos Seminários de Zollikon, apresenta reflexões sobre o ser-doente relacionando a doença como limitação no poder-ser do Dasein e, consequentemente, como restrição à sua liberdade (Heidegger, 2006; Nogueira, 2008). Ele considera que a doença mental acarreta uma perturbação na abertura primordial do Dasein em relação ao mundo e traz diferenças na sua relação com o tempo e o espaço, isto é, na forma de estar presente no mundo (Heidegger, 2006; Nogueira, 2008). Em relação à alucinação, ele coloca que:

O alucinado só pode ver seu mundo através de um estar presente imediato, sensorialmente perceptível de todos os fatos, porque ele não pode lidar com o presente e o ausente - porque ele não pode se mover livremente em seu mundo. [...] Para a compreensão das alucinações não se deve partir da diferenciação entre 'real' e 'irreal', mas, sim, do exame do caráter de relação com o mundo em que o paciente se encontra no momento (Heidegger, 2006, p. 175-176)

Deste modo, e a partir destas considerações, recoloca-se o Real segundo a constituição própria de cada um. $\mathrm{O}$ vivido e o experienciado são reais como evidências. Porém é uma realidade que não suporta uma crítica posterior ao ocorrido (Merleau-Ponty, 1994, p. 382): sua existência não é uma verdade ideal ou lógica. O verdadeiro, entendido como vivência da evidencia da verdade, apresenta-se como uma síntese que organiza os elementos da existência. Assim o que sustenta a noção de realidade é uma noção interna; Husserl a chama de intuição originária (Dartigues, 1973). É a evidência interna, pré-lógica e racional, por essência indefinível, que nos torna existentes ativos no contexto em que vivemos. $\mathrm{O}$ segundo fato que demonstra que a alucinação segue uma lógica que não se 
define pela presença ou não de uma falsa percepção estrita, é o de haver uma diferenciação interna, de estrutura, entre o 'real' e o 'irreal' (o sonho, a imaginação, a ilusão ou a alucinação).

A concepção clássica da alucinação, definida como a "de uma percepção sem objeto determinada por uma razão endógena e verificada por um critério empírico" (Campos e Coelho Jr., 2002, p. 15) espelha uma determinação causal na psiquiatria e desconsidera a questão do sentido na existência humana.

Uma descrição existencial da concepção da alucinação nos dita que esta é um fenômeno de interrupção das possibilidades; na linguagem psicopatológica dos fenomenólogos (Binswanger, 2001; Merleau-Ponty, 1994; Pérola, 2006) ocorre a paralização da temporalidade. A espacialidade toma aspecto de paisagem, tornando-se estagnada e sem profundidade. Assim, na alucinação coloca-se o mundo subjetivo em alta conta, subestimando a temporalidade e espacialidade dadas, e a 'percepção' originária substitui a aparição dos fenômenos (Merleau Ponty, 1994; Campos e Coelho Jr., 2002). Observe que quando um doente diz 'ver' um duende, ele apenas adequou uma impressão à linguagem, mas não o 'viu' de fato (Merleau-Ponty, 1994). Entretanto se para ele a significação do duende possui uma representação real, esta é sentida e experienciada como real.

$\mathrm{O}$ alucinado encontra-se num outro tempo, que se distancia das outras coisas e das outras pessoas (Minkowski, 2002), isto é, a realidade partilhada intersubjetivamente. Entretanto, Merleau-Ponty (1994) remete ao fato de que os alucinados não percebem as alucinações como totalmente reais: diferenciam-nas do mundo compartilhado. Se interrogados, admitem que há um tipo diferente de percepção ocorrendo; não se trata de uma 'percepção direta'. Um homem de casaco vermelho e estatura mediana, igual a uma alucinação descrita, colocado no jardim onde ocorria a alucinação é distinguido da falsa-percepção; uma paciente se assusta quando há de fato pó de arroz, no travesseiro onde antes ela apenas o alucinava; sensações de corrente elétrica se diferem de uma voltagem aplicada.

Portanto, deve-se dar um sentido diferente do habitual quando um doente diz que 'viu' um demônio envolto em fumaça. Além disso, doentes diferenciam alucinações de percepções comuns pelo detalhamento e pela relação que aquelas possuem com o resto do mundo; o fluxo difere; os detalhes do objeto alucinado ficam menos concretos, e a alucinação aparece sempre com certa fisionomia, um estilo, mas nunca é vista de fato. Mesmo assim, a alucinação não se trata de um 'julgamento’: seu sentido é mais profundo que isto, ela possui relação com a existência (Merleau-Ponty, 1994).

Segundo Merleau-Ponty (1994), todo conhecimento se fundamenta em uma "fé perceptiva" que remete à realidade; a intersubjetividade e as concepções de realidade e ilusão estão presentes no ato de perceber a realidade
(Campos \& Coelho Jr., 2002). Deste modo, a alucinação e o estar patológico são possibilidades intrínsecas ao serno-mundo. $\mathrm{O}$ alucinado toma por realidade um mundo análogo, que considera primordial, isto é, rompe a comunhão pré-reflexiva entre o homem e o mundo (Campos \& Coelho Jr., 2002).

O homem normal também possui, como afirma Merleau-Ponty (1994), a "ferida da subjetividade"; entretanto sua existência está mais voltada para o mundo objetivo e dispensa a preponderância da subjetividade. $\mathrm{O}$ doente tem sobre o tempo (e poderíamos dizer sobre o espaço também) uma “tomada franca e ingênua” (p. 347), que o desapropria da percepção comum. Assim, para Merleau-Ponty (1994) o fenômeno alucinatório contém uma chave para destituir as teorias empíricas e intelectualistas; e proporcionam o descarte da apoditicidade que se tem sobre o tempo e sobre a percepção.

A estrutura da percepção na alucinação é diferente da percepção normal, pois ela "diz respeito a uma desarticulação da comunhão intersubjetiva pela fixação em uma única perspectiva, criando um espaço de paisagem que será reconhecido como uma manifestação exterior por intermédio de uma conduta despersonalizada do corpo fenomenal" (Campos \& Coelho Jr., 2002, p. 22). Entretanto, enquanto expressão existencial de um vivido, ela está repleta de sentido.

Deste modo, a alucinação como patologia existencial auxilia a subverter a concepção clássica e cartesiana do ego, apontando para a comunhão pré-reflexiva entre o sujeito e o mundo, para este saber originário sobre aquele e este, este indeterminado e sem controle (Mantovani, 2009; Zanoni \& Serbena, 2011). A patologia ou doença se apresenta então como um modo diverso de ser no mundo, onde existe dificuldade em lidar com este indeterminado e aonde as fronteiras entre eu, mundo e outro tornam-se tênues e confusas, implicando em uma "indistinção entre a voz própria e do outro ou confusão alucinatória” (Vieira \& Furlan, 2011, p. 140). Assim, a patologia acarreta uma modificação na comunicação e na linguagem, sendo um fenômeno expressivo e de estreitamento do campo do vivido (Campos \& Coelho Jr., 2002).

\section{O Sentido na Alucinação}

A partir destas considerações, ressalta-se que o alucinado deve ser considerado na sua dimensão de existente, e que ele constrói uma realidade que não possui a profundidade vivida ou experienciada encontrada nas relações com o mundo real compartilhado (Merleau Ponty, 1994). Assim, a alucinação está inserida na realidade, neste encontro sujeito-mundo particular do sujeito; ela comporta um projeto ou finalidade deste ser-aí no seu mundo. Importa fundamentalmente não a causa do alucinar, mas o seu sentido e sua inserção no mundo do sujeito, pois todo ato encontra uma gênese no modo existencial da 
pessoa; todos os atos se relacionam constituindo a maneira de ser da pessoa (Merleau-Ponty, 1994). Disto decorre que uma 'falsa percepção' pode ser inquerida quanto ao motivo e à necessidade que ela tem de aparecer. Por isso Merleau-Ponty (1994) afirma que o sujeito sabe quando está alucinando. Sendo que reside a alucinação nesta explicação paradoxal da relação entre corpo e a percepção - o corpo e os sentidos afirmam a realidade, mas a mente nega (ou vice-versa).

No seu o caráter ontológico, isto é, relativo ao ser da alucinação, ao que a distingue dos outros fenômenos, não interessa se o objeto alucinado tenha existência concreta ou não (Heidegger, 2002; 2006). Se o objeto existe para o sujeito, significa que ele possui uma realidade para o mesmo, tal qual os outros fenômenos. Este objeto pode não aparecer para as outras pessoas, mas o Eu (sujeito) tem relação com ele, e não há necessidade de provar pois ela é possibilitada pela abertura do ser-aí no mundo. Abertura que permite integrar as coisas dadas segundo uma lógica que cabe ao ser-aí formular ou desenrolar. A alucinação, apesar de poder ser diferenciada dos objetos comuns pela espacialidade caracteristicamente dissociada da espacialidade mundana e compartilhada, tem uma existência para o ser-aí ou sujeito em relação com ela.

Deste modo, é fundamental investigar como se dá para uma consciência ser palco de um mundo onde a alucinação é possível. Vista em seu aspecto ontológico (onde, para o ser é irrelevante o caráter de realidade mensurável), a alucinação se abre muito mais como caráter simbólico que surge num terreno fértil característico da abertura ao mundo que é da consciência (Heidegger, 2006). Esta abertura e transcendência do ser-aí diante do mundo possibilitam a imaginação e, consequentemente, a alucinação. Justamente o que aproxima o imaginar e o alucinar é o fato de tornar-presente algum lugar onde não 'estamos' juntos fisicamente (Heidegger, 2006).

O tornar-presente (algum lugar distante) é permitido ao homem justamente por sua capacidade de não ser 'simplesmente dado' como um sapato ou uma xícara. Podemos tornar-presente uma antiga casa na qual estivemos. Dela ressaltamos alguns detalhes, onde cada pessoa 'verá' alguma coisa diferente, por exemplo, uma parede ou uma pintura. Entretanto, não estamos presentes na casa antiga, mas mesmo assim, estamos juntos abertos para a casa que conhecemos. É importante ressaltar que enquanto tornamos-presente algum lugar, não acreditamos estar realmente lá. A isso, segundo Heidegger (2006), chamamos de imaginar. Portanto, é uma falha na abertura em relação ao mundo que faz um esquizofrênico se perder do mundo, pois este 'acredita' (diz acreditar) serem reais os delírios e alucinações que cria, não mais estando a ele ser possível perceber e captar o mundo. Do mesmo modo, o alucinado terá um motivo que faz com que o objeto imaginado tenha prevalência excessiva e com estatuto de realidade.
Desta forma, a alucinação não pode ser reduzida a uma explicação causal e redutiva. Ela não pode ser explicada apenas por uma causa endógena, tal como uma disfunção orgânica ou psíquica; ou por uma causa exógena como ingestão de substâncias (Jaspers, 2005). Ela se configura como um modo de ser do sujeito no encontro com o mundo. Deste modo, ela possui o caráter da expressão de um sentido e de uma tomada de posição do sujeito diante da realidade. Isto implica que na alucinação está envolvida a totalidade do sujeito. Este adoecimento não se dá em sua consciência ou na parcela referente a juízos de realidade, mas no nível pré-reflexivo. No qual existe uma comunhão entre o corpo e o mundo e se dá o saber originário do qual derivam os outros, inclusive o psicológico e o psiquiátrico (Merleau-Ponty, 1994; Heidegger, 2002; 2006).

$\mathrm{O}$ adoecimento ou patologia se torna assim uma janela ou caminho para este sentir puro (este solo) que implica e contém uma fé perceptiva implícita na percepção da realidade do mundo e dos outros, isto é, a evidência pré-reflexiva de que o que se percebe e vivencia é real e verdadeiro no sentido de não ser ilusão ou fantasia. Neste solo, se funda a ilusão do conhecimento; se confundem o Eu, o mundo e o Outro e se revela a indeterminação e a impossibilidade de controle de mundo. Portanto, o adoecimento, a alucinação e a patologia são possibilidades de ser de todo o sujeito no mundo se este sujeito se confunde com o mundo, estreita suas possibilidades vivenciais e modifica sua comunicação com os outros, pois a ele sobra ou falta algo em lidar com a realidade. Se o adoecimento ocorre neste nível da relação, também a cura - por meio da linguagem e da comunicação com o Outro - deve ocorrer neste nível, recuperando a expressividade, as fronteiras entre o Eu, o mundo e o Outro (Vieira \& Furlan, 2011). Para isso, a conduta, a sua reflexão e expressão não podem se solidificar, limitando-se a ser "palavra falada”, porém consistir numa expressão pessoal e autêntica da realidade vivida, uma "palavra falante” (Luijpen, 1973).

Observa-se que a alucinação, neste contexto e abordagem, não é vista como apenas um indicador ou sintoma (Minkowski, 2000), mas uma conduta que expressa um sentido que pode e deve ser comunicado e partilhado para poder recuperar parte da profundidade do vivido. A alucinação é uma conduta expressiva como qualquer outra, não pertencendo a uma categoria específica tal como o sintoma, não sendo - essencialmente - própria da patologia. Ela se apresenta como uma possibilidade da existência 'saudável' (Minkowski, 2000) e, inclusive, existe em algum grau nesta existência dita 'sadia' ou 'normal'. Ao considerar a alucinação deste modo, também se podem modificar as concepções de outras condutas tidas como 'patológicas' (Holanda, 2001); pois elas se constituem possibilidades de ser no mundo e, como tal, também possuem um sentido e o expressam. A patologia pode deixar de ser apenas um estigma para se tornar um caminho de recuperação e alargamento de nossas próprias possibilidades de sentido e de existir. 


\section{Referências}

Amaral, M. (2007). Alucinações: a origem e o fim de um falso paradoxo. J. Bras. Psiquiatr., 56(4), 296-300.

Binswanger, L. (2001). Sobre a psicoterapia. Revista Latinoamericana de Psicopatologia Fundamental, 4(1), 143-166.

Campos, E. B. V. \& Coelho Jr., N. E. (2002). O conceito de alucinação em Merleau-Ponty: aspectos clínicos e psicopatológicos. Revista Latinoamericana de Psicopatologia Fundamental, 2, 13-27.

Chaui, M. (2000). Convite à filosofia. São Paulo: Ática.

Dartigues, A. (1973). O que é a fenomenologia. Rio de Janeiro: Eldorado.

Descartes, R. (1983). Meditações em Os Pensadores. São Paulo: Abril Cultural. (Original publicado em 1641).

Hebeche (2005). A imaginação em Descartes e Kant. Veritas: revista da Pontificia Universidade Católica do Rio Grande do Sul, 50(2), 99-110.

Heidegger, M. (2002). Ser e tempo. Petrópolis, RJ: Vozes.

Heidegger, M. (2006). Seminários de Zollikon. Petrópolis, RJ: Vozes.

Holanda, A. (2001). Psicopatologia, exotismo e diversidade: ensaio de antropologia da psicopatologia. Psicologia em Estudo, 6(2), 29-38.

Jaspers, K. (1987). Psicopatologia geral. Rio de Janeiro: Livraria Atheneu.

Jaspers, K. (2005). A abordagem fenomenológica em psicopatologia. Revista Latinoamericana de Psicopatologia Fundamental, 8(4), 769-787.

Kaplan (1997). Compêndio de psiquiatria: ciência do comportamento e psiquiatria clínica. Porto Alegre: Artes Médicas.

Kolb, L. C. (1986). Psiquiatria clínica. Rio de Janeiro: Guanabara.

Locke, J. (1999). Ensaio sobre o entendimento humano em Os Pensadores. São Paulo: Abril Cultural. (Original publicado em 1690).

Luijpen, W. (1973). Introdução à fenomenológia existencial. São Paulo: Editora Universitária e Pedagogica.

Mantovani, H. J. (2009). Uma fenomenologia do patológico em Merleau-Ponty. Rev. Filos., Aurora, Curitiba, 21(28), 193-212.

Menezes Jr, A. \& Moreira-Almeida, A. (2009). O diagnóstico diferencial entre experiências espirituais e transtornos mentais de conteúdo religioso. Rev Psiq Clín. 36(2), 75-82.

Merleau-Ponty, M. (1994). Fenomenologia da percepção. São Paulo: Martins Fontes.

Minkowski, E. (2000). Breves reflexões a respeito do sofrimento (aspecto pático da existência). Revista Latinoamericana de Psicopatologia Fundamental, 3(4), 156-164.
Minkowski, E. (2002). A noção do tempo em psicopatologia. Revista da Associação Psicanalítica de Porto Alegre - Clínica da adolescência, 23, 109-126 (Original publicado em 1929).

Nogueira, R. P. (2008). Stress and suffering: an Heideggerian interpretation. Interface - Comunic., Saúde, Educ., 12(25), 283-93.

Parra, A. (2008). La "visión del aura” como experiencia alucinatoria en individuos no-clinicos. Psico-USF, 13(2), 277-286.

Pérola, I. A. S. (2006). Sonho e alucinações visuais: propostas fenomenológicas para sua compreensão, interpretação e intervenção psicológica. Análise Psicológica, 24(3), 343-352.

Ramos, R. T. (2006). O exame psíquico: aparência e comportamento, consciência, atenção, orientação, memória, senso percepção, pensamento, afetividade, juízo, crítica e pragmatismo. Em Abreu, C. N. et al. Síndromes psiquiátricas: diagnóstico e entrevista para profissionais de saúde mental. Porto Alegre: Artmed, 25-30.

Vieira, M. G. \& Furlan, R. (2011). Algumas considerações sobre psicopatologia na filosofia de Merleau-Ponty. Ágora (Rio de Janeiro), 14(1), 129-141.

Zanoni, A. P. \& Serbena, C. A. (2011). A Psicopatologia como uma experiência da alma. Revista Latinoamericana de Psicopatologia Fundamental, 14(3), 485-498.

Carlos Augusto Serbena - Professor Adjunto do Departamento de Psicologia da Universidade Federal do Paraná, Membro do Laboratório de Fenomenologia e Subjetividade (LabFeno-UFPR). Endereço Institucional: Depsi/UFPR, Praça Santos Andrade, n 50, Sala 215 (Ala Alfredo Buffren), CEP: 80-020.300. Curitiba - PR. Email: caserbena@yahoo.com

Felipe Montrucchio Ilkiu - Psicólogo, graduado pela Universidade Federal do Paraná. Email: felipemont_lp@hotmail.com

Recebido em 25.08.14 Primeira Decisão Editorial em 23.11.15 Aceito em 02.03.16 